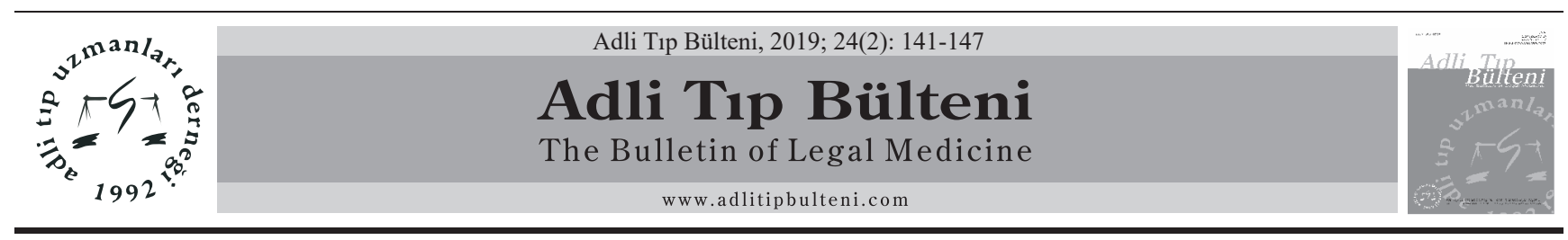

DERLEME / REVIEW

\title{
Sinsice İşlenen Bir Suç: Madde ile Kolaylaştırılmış Cinsel Saldırılar ve Fail Tipolojisi
}

\section{A Predatory Crime: Drug Facilitated Sexual Assaults and Perpetrator Typology}

Sunay Firat*, Mehmet Aykut Erk

\section{$\ddot{O ̈ z}$}

Madde ile Kolaylaştırılmış Cinsel Saldırı (MKCS), mağdur alkol ve/veya herhangi başka psikoaktif madde etkisindeyken veya sedasyon ve hipnotik etkisi bulunan başka psikoaktif maddeler aracılığıyla mağdurun faile karşı koyamaz duruma geldiğinde yönlendirdiği cinsel saldırı türüdür. MKCS, cinsel saldırının doğası gereği mağdurun bilincini kazandıktan sonra durumu bildirmesinden ötürü titiz bir çalışmayı gerektirir.

$\mathrm{Bu}$ çalışmanın amacı maddeyle kolaylaştırılmış cinsel saldııının faili konumunda bulunan bireylere risk faktörlerini ve yine suça neden olan olası ruhsal ve kişilik bozukluklarını literatür temelli incelemek; suç ve davranış bilimlerine, penolojik müdahalelere ve rehabilitasyon girişimlerine farklı bir bakış açısı oluşturarak katkı sağlayabilmektir.

MKCS'nin faili herhangi bir psikopatolojisi olmayan sağlıklı bireyler de olabilmektedir. Ancak yapılan çalışmalarda ortaya çıkan birtakım bulgulara göre fail, olguya özgü farklı kişilik özellikleri gösterebilmektedir. MKCS failleri meydana getirdikleri davranışın yasadışı olduğunun farkındadır ancak bu davranışlarını kendi etik yargılarına göre yanlış bulmamaktadır. MKCS, yüksek düzeyde davranış bilimleri ve toksikoloji bilgisi gerektirmektedir. Failin sahip olduğu bu nitelikler, amacına ulaşmasında ve sonrasında adli süreç için en önemli tanık olan mağdurun yaşadıklarının farkına varmaması adına faile kolaylık sağlamaktadır.

Sonuç olarak MKCS’nin iyi bir tanımının yapılması bu olgulara yaklaşımlar açısından önemlidir. Kapsamlı ve araştırmacılar tarafindan kabul gören bir tanım gelecekte yapılacak araştırmalar ve toplumsal farkındalık için oldukça faydalı olacaktır. Ülkemizde ne yazık ki modern anlamda Cinsel Saldırı Kriz Merkezlerinin olmayışı cinsel saldırı olgularında mağdur için gerekli olan tıbbi, psiko-sosyal ve hukuki desteğin sağlanmasına engel teşkil etmektedir. MKCS gibi cinsel saldırı türlerine ve bunların sonuçlarına dikkat çekilmeli, gerekli merkezler ve bilinçlendirme kampanyaları ile bu konular gündemde tutulmalıdır.

Anahtar Kelimeler: Madde ile Kolaylaştırılmış Cinsel Saldırı; Fail Tipolojisi; Suçun İşlenişi.

\section{Abstract}

Drug Facilitated Sexual Assault (DFSA) is a type of sexual assault which occurs when victim is vulnerable to perpetrator's attack due to sedation and hypnotic effects of the higher amount of consumption of alcohol and/or another psychoactive drug. By its very nature of sexual assault, DFSA has to be taken carefully after the victim restores his/her consciousness.

The aim is to contribute to the Crime and Behavioral Sciences, penological interventions and rehabilitation attempts by examining how the perpetrators' risk factors, possible mental or personality disorders in their developmental history and perpetrators' characteristics affect the sexual offenses based on recent literature.

The perpetrator of DFSA can be a person that has any other psychopathological history. However, according to some research results perpetrator may portray different characteristics for each case. Even if the perpetrator of DFSA acknowledges the behavior of himself/herself, he/she does not give any moral reaction to alleged behavior. DFSA requires high knowledge of behavioral sciences and toxicology. Those requirements of perpetrator help him/her by making victims unconsciousness and let him/her get what he/she desires. After all the victim may or may not realize what does happen to him/her.

To sum up it is important to have a firm definition of DFSA in order to approach profoundly to those incidents. An extensive definition will be useful for the latter researches. Due to the fact that Turkey has not got any Sexual Assault Crises Center in a modern meaning, the medical, psycho-social and legal aid which victim needs cannot be given.

Keywords: Drug Facilitated Sexual Assault; Perpetrator Typology; Modus Operandi.
DOI: $10.17986 / \mathrm{blm} .2019250175$

Sunay Frrat: Doç. Dr., Çukurova

Üniversitesi Sağlık Bilimleri Fakültesi

Psikiyatri Hemşireliği Anabilim Dalı,

Adana

Eposta: sunayfirat@gmail.com ORCID ID: https://orcid.org/0000-00029960-0836

Mehmet Aykut Erk: Psk. Dan., Çukurova Üniversitesi, Bağımlılık ve Adli Bilimler Enstitüsü, Bağımlılık Anabilim Dalı Adana Eposta: maykuterk@gmail.com ORCID ID: https://orcid.org/0000-00024362-2729

Bildirimler/ Acknowledgement: Yazarlar bu makale ile ilgili herhangi bir çıkar çatışması bildirmemişlerdir. Yazarlar bu makale ile ilgili herhangi bir finansal destek bildirmemişlerdir. The authors declare that they have no conflict of interests regarding content of this article.

The Authors report no financial support regarding content of this article.

Geliș: 20.10 .2018

Düzeltme: 02.11.2018

Kabul: 08.11.2018

p-ISSN: $1300-865 \mathrm{X}$

e-ISSN: $2149-4533$ 


\section{Giriş}

Yirminci yüzyılın son çeyreğinden bu yana dezinhibisyon, sedasyon ve amnezi gibi etkilerinden dolayı hem reçeteli veya sokakta satılan psikoaktif maddelerin resmi olmayan satışındaki artış hem de failler tarafından kullanımındaki artış ile beraber Madde ile Kolaylaştırılmış Cinsel Saldırı (MKCS) şüphesiyle Cinsel Saldırı Kriz Merkezlerine başvuran olgulardaki fazlalaşma dikkatleri bu konu üzerine çekmiştir (1). İngiltere, Birmingham'da MKCS şüphesiyle yapılan toksikolojik analizlerin oranı 2002'den 2004 yılına kadar \%77 artmıştır (2). Amerika Birleşik Devletleri'nde ise "İçeceğine Dikkat Et" gibi farkındalık uyandıran kampanyalarla MKCS'ye dikkat çekilmiş ve üniversite kampüslerinde kamu lehine çalışmalarda bulunulmuştur (3).

MKCS failin mağdura; alkol veya herhangi başka psikoaktif madde etkisindeyken veya sedasyon ve hipnotik etkisi bulunan başka psikoaktif maddeler kullanarak mağdurun faile karşı koyamaz duruma geldiğinde yönlendirdiği cinsel saldırı türüdür. MKCS'de mağdur davranışlarının kontrolünü sağlayamayacak kadar çok madde etkisi altındadır (4).

Horvarth ve Brown (2005), MKCS tanımını iki ayrı şekilde yapmıştır. Proaktif MKCS, failin mağduru etkisiz hale getirmek, davranışlarını yönlendirme yeteneğini ortadan kaldırmak amaciyla gizlice ya da zor kullanarak dezinhibisyon ve sedasyon yaratacak maddeyi cinsel saldırı ereğiyle kullandığı bir tanımken, Fırsatçı MKCS ise halihazırda kendi isteğiyle bilincinin bir kısmını ya da tamamını yitirecek düzeyde alkol veya madde kullanmış olan mağdurun zayıflığından faydalanarak gerçekleştirilen cinsel saldırı olarak tanımlanmıştır (5).

Literatürdeki bir diğer adlandırma ise Yırtıc1/Avc1 (Predatory) MKCS'dir. Bu tanıma göre istemli olarak kullanıldığı belirtilmeyen merkezi sinir sisteminin işleyişine etkide bulunan maddelerin bulgusuna ulaşıldığ 1 cinsel saldırı türüdür. Diğer tanımlara yakın olarak bu tanımda da eylem, fail tarafindan mağdurun içkisine mağdur farkında olmadan madde karıştırmayı göz önünde bulundurmaktadır (6).

Görüldüğ̈̈ üzere MKCS'nin gerçekleşme örüntüsüne göre farklı tanımlamalar yapılsa da araştırmacıların ortaklaştıkları noktalar; mağdurun bilgisi dahilinde olmayan hile içeren yaptırımlar ve mağdurun halihazırda davranışlarını etkileyen madde kullanımının varlığıdır.

Bu çalışmanın amacı MKCS'nin faili konumunda bulunan bireylere risk faktörlerini ve yine suça neden olan olası ruhsal ve kişilik bozukluklarını literatür temelli incelemek; suç ve davranış bilimlerine, penolojik müdahalelere ve rehabilitasyon girişimlerine farklı bir bakış açısı oluşturarak katkı sağlayabilmektir.

\section{Dünya Üzerindeki Yaygınıı Çalışmaları}

MKCS, cinsel saldırının doğası gereği mağdurun bilincini kazandiktan sonra durumu bildirmesi, bazen de mağdurun olayların farkına vardığında cinsel saldırıya maruz kalıp kalmadığının şüphesi dolayısıyla titiz bir çalışmayı gerektirir. Yapılan yaşam-boyu yaygınlık çalışmalarında ulusal bazda kadınlara yönelik cinsel saldırı oranları $\% 12$ ile $\% 18$ arasındadir $(4,7,8)$.

Yine başka yaygınlık çalışmalarında yaşamları boyunca yaklaşık olarak her 3 kadından biri, her 6 erkekten biri cinsel şiddete maruz kalırken, her 5 kadından biri tamamlanmamış ya da tamamlanmış cinsel saldırıya/ tecavüze maruz kalmıştır (9). İngiliz Suç Tarama araştırmasına göre cinsel saldırı mağdurlarının $\% 5$ 'i istemsiz bir biçimde madde etkisindeyken cinsel saldırıya uğradıklarını belirtirken, $\% 15$ 'i cinsel ilişki için gereken r1zayı gösteremeyecek kadar yüksek oranlarda alkol etkisi altında olduklarını belirtmişlerdir (10).

Amerika Birleşik Devletleri'nde telefon kanalıyla gerçekleştirilen cinsel saldırı odaklı bir survey çalışmasında katılımcıların \%2,3'ü alkol veya psikoaktif maddeler ile kendi kendilerini istemli bir biçimde etkisiz hale getirdiklerini ve faillerin de bu durumlarını kullandıklarını bildirmişlerdir (4).

Cinsel saldırı olgularının çoğunluğunda (\%50-77) mağdurun istemli olarak alkol kullandığı belirtilmektedir $(11,12)$. Bu oranlardan hareketle Richer ve arkadaşlarının (2017) yürütmüş olduğu çalışmada incelenen tüm cinsel saldırı olguları içerisinde MKCS-İstemsiz \%29,2 iken, MKCS-İstemli \%23,1 (n=390) oranındadır (13).

\section{Kanada}

Du Mont ve arkadaşlarının 2009 yılında yapmış oldukları çalışmada ise cinsel saldırı olarak nitelendirilen 882 olgunun \%20,9’u MKCS olarak tanımlanmıştır (1).

Takip eden senede yapmış oldukları çalışmada ise Du Mont ve arkadaşları (2010) Kanada'nın Ontario bölgesindeki MKCS olgularının tedavisini üstlenen 7 hastane baz11 Cinsel Saldırı Kriz Merkezine başvuran 178 mağdurun idrar örneklerinde \%30,9 ethanole rastlamışken, Kannabis $\% 33,7$, Kokain $\% 21,4$, Amfetaminler \%7,3, MDMA (Ekstazi) \%7,3 ve GHB (Gama Hidroksibütrik Asit) \%1,1 oranında tespit edilmiştir (14).

\section{Birleşik Krallık}

Scott-Ham ve Burton'un (2005) yayımladığı detaylı çalışmada, 1014 MKCS olgusundan sadece alkolün olduğu veya alkole eşlik eden başka bir psikoaktif maddenin de mevcut olduğu oranlar \%46 olarak bulunmuştur. Kannabis kullanımı $\% 26$ oranındayken kokain kullanım oranı 
ise tüm olguların \%11'ini kapsamaktadır. Cinsel saldırı şüphesi ile gelen örneklerin \%72'sinin 24 saat içerisinde toplanmasına rağmen ilginç bir şekilde A.B.D merkezli çalışmaların aksine bu çalışmada GHB ve Flunitrazepam gibi maddelere hiç rastlanılmamıştır (15).

Hindmarch ve arkadaşları (2001) 4 yıl boyunca MKCS şüphesiyle gelen 3303 mağdurun idrar örneklerini incelediği çalışmasında, mağdurların örneklerinden $\% 61$ 'i en az bir psikoaktif maddeden pozitif sonuç verirken \%39'u negatif sonuç vermiştir. Pozitif sonuç veren örneklerden \%64'ünde sadece bir psikoaktif madde; \%22'sinde iki psikoaktif madde ve \%14'ünde üç ya da daha fazla psikoaktif madde bulunmuştur. Alkol ise \%44 oaranında tek başına görülürken, $\% 23$ oranında başka maddelerle birlikte bulunmuştur. \%67 ile pozitif örneklerde en yüksek oranda tespit edilen maddedir. Alkolden sonra ise en s1k tespit edilen maddeler ise; \%18,6 ile Kannabis, \%8,4 ile Kokain, \%6,7 ile Amfetaminler ve \%3 ile GHB (gamma hydroxybutyrate)'dir (16).

\section{Fransa}

Fransa'daki araştırmalar gerek analiz yöntemlerinin netleştirilmemesi gerekse büyük çaplı örneklemlerin eksikliğinden dolayı oldukça azdır. Günümüze kadar limitleri bakımından daha tutarlı olan 1996'da Boussairi ve arkadaşlarının (1996) gerçekleştirmiş olduğu çalışmada MKCS şüphesiyle gelen 35 mağdur incelenmiştir. Mağdurlar, içkilerinin gizlice ilaçlandığını düşünmekte ve akabinde cinsel saldırıya ya da hırsızlığa maruz kaldıklarını belirtmişlerdir. Toksikolojik analizler sonucunda ABD ve Birleşik Krallıktaki çalışmalardan farklı olarak benzodiazepin oranlar1 \%48,5 ile \%17,1 olan kannabis ve $\% 11$ olarak tespit edilen alkol oranlarından daha yüksek çıkmıştır (17).

\section{İsveç}

2008 yılında cinsel saldırı iddiasıyla gelen mağdurlardan alınan 1806 örneğin incelendiği çalışmada örneklerin $\% 31$ 'inde alkol ya da herhangi bir psikoaktif madde bulgusu tespit edilmemiştir. Ancak bu çalışmanın bütün cinsel saldırı olgularını incelediğini belirtmekte fayda vardır. Buna rağmen örneklerin \%43'ünde alkol metaboliti bulunmuştur. \%12'sinde alkol ve psikoaktif madde metaboliti beraber tespit edilmişken, alkol hariç sadece psikoaktif madde tespit edilen örnek oran1 \% 15 ’tir (18).

\section{Avustralya}

Hurley ve ark. (2006) yaptığ sel saldırı olgusundan 76's1 MKCS olarak nitelendirilmiştir (11).

\section{Fail}

Diğer cinsel saldırı türlerinden farklı olarak MKCS'nin faili herhangi biri olabilmektedir. Ancak literatürdeki çalışmalarda ortaya çıkan birtakım bulgular göstermektedir ki, fail olguya münhasır karakteristiklere sahip olabilmektedir. MKCS failleri diğer cinsel saldırı faillerinden, gelişmiş iletişim becerileri ve sosyal becerileriyle ayrılmaktadırlar (19).

MKCS fark edilmediği takdirde failler tarafindan tekrar işlenebilecek bir düzeneğe sahiptir. MKCS failleri meydana getirdikleri davranışın yasadışı olduğunu çok iyi bilmekte ancak bu davranışlarını kendi etik yargılarına göre yanlış bulmamaktadır. Kernberg (1989)' e göre Patolojik Narsist, gücün sömürücü bir şekilde kullanılmasıyla insanlar üzerinde hak talep edebileceğini öngörür (20). Bu bakış açısı MKCS failinin tanımlamasını yapabilecek düzeydedir (21).

Yapılan bir çalışmaya göre üniversite öğrencilerine daha önce hiç MKCS olgusuyla karşılaşıp karşılaşmadıkları ve bu davranışın nedeni sorulmuştur. Kendisinin veya bir başkasının MKCS olgusuyla karşılaştığını belirten bireylerin yanıtları arasında başka birinin içeceğine madde karıştırmanın eğlence amaçlı olduğu veya tamamen cinsel saikler dolayısıyla meydana geldiği bulunmaktadır. $\mathrm{Bu}$ yanıtlar cinsiyetlere göre farklılaşmaktadır. MKCS olgusunun mağduru olmuş ya da bu olaya tanık olan kadınlar, faillerin cinsellik ya da cinsel saldırı amacıyla içeceklere madde karıştırdığını düşünürken erkekler faillerin eğlence amaçlı bu davranışı gerçekleştirdiğini öne sürmektedir (22).

MKCS'nin faili, eylemi eğlence amaçlı gerçekleştirdiğini söyleyip mağdurun bilinçsiz halinden faydalanmayacak olsa bile karşısındakinin rızası olmadan içeceğine bir madde karıştırması zorlayıcı ve kontrol altına alıcı bir davranıştır. Zorlama, kontrol altına alma gibi davranışlar kişilerarası saldırganlık literatüründe adı geçen davranımlardır (19). Benzer olarak Malamuth ve arkadaşlarının (1995) geliştirdiği birleşim modeline göre erkeklerin kadınlara yönelttiği cinsel açıdan saldırgan tutumların sebebini kadını kontrol altına alma düşüncesi ve üstün gelme çabası olarak açıklanmaktadır. Kadının başkaları tarafından çekici olarak algılanabilir. Ancak söz konusu kadının gösterdiği sağlam duruş, zorlayıcı davranışlar ile cinsellik arayışı içinde olan ve cinsel saldırganlığa yatkın bir erkek tarafından tehdit olarak algılanabilir (23).

Faillerin psikotik bulgulara sahip olduğu MKCS olguları daha az sıklıkta görülmektedir. Sadece bir olguda 55 yaşında evden çalışan bir yazar olan fail, ev işleri için bir asistana ihtiyaç duymaktadır. Verdiği ilana istinaden iş başvurusuna gelen kadın çalışanlara bipolar bozukluğunun mani döneminde iken MKCS girişimlerinde 
bulunmuştur. Yarg1 sürecinde ise davranışının doğru olmadığını kabul etse dahi, mahkeme tarafından ehliyetsiz bulunmamıştır. Ancak yaşadığı psikiyatrik bozukluğun mani dönemindeki karakteristik özelliklerinden olan artmış cinsel isteğin de bu durumda etkili olacağı not edilmelidir (19).

Bazı kompulsif faillerin aksine MKCS failleri yaşananlardan sonra mağdurlarla empati yapmaktan uzaktır. Genellikle suçu reddederler ve mağdurlarını bir av olarak görürler. Ortamın ve koşulların uygun olduğu anlarda harekete geçerler ve eylemi en kesin şekilde gerçekleştirmekten çekinmezler. MKCS failleri eylemlerini, tekrar gerçekleştirebilmeleri adına uygun şekillerde işlerler. Bu yüzden sağlık sorunları ve güvenlikle ilgili ciddi bir bilgi birikimine sahiptirler. Sosyal yargıdan ve suçluluktan kaçınmak adına bu bilgilerini kullanarak saldırılarını büyük bir titizlikle ortaya koyarlar (24).

MKCS yüksek düzeyde toksikoloji ve davranış bilimleri bilgisi gerektirmektedir. Buradan hareketle denebilir ki MKCS failleri suçluluklarının ortaya çıkmaması adına bu alanlarda sofistike bilgi birikimine sahip bireylerdir. Cinsel saldırının gerçekleşebilmesi için (MKCS-İstemsiz) GHB, flunitrazepam gibi sedatif etkili psikoaktif maddelerin temini gerekmektedir. Kokusuz ve tatsiz olan bu maddeler içkilere kolaylıkla karıştırılabilir. Ancak daha yüksek sedatif etkiye sahip diazepam/diazem ise yeterli miktarda farmakoloji bilgisine sahip failler tarafindan tercih edilmektedir. Hizlı intoksikasyon etkisi sebebiyle kullanımı görülmektedir. MKCS en etkili şekilde işlendiği zaman mağdur tarafindan saldırının emareleri fark edilememektedir (19).

Yapılan başka bir çalışma, MKCS-İstemsiz faillerinin eylem için gereken maddeleri nereden temin edeceklerini ve nasıl kullanabileceklerini sosyal medya ve çevrim-içi pornografik forumlar sayesinde öğrenip saldırı planlarını ona göre oluşturduklarını vurgulamaktadır (13).

Fail-mağdur yakınlığı açısından MKCS olgularındaki failler, Ehliyetin Olmadığı Cinsel Saldırı olgularındaki (mağdurun davranışlarını yönlendirme yeteneğinin azaldığı/kaybolduğu) faillere göre, mağdur tarafindan çoğunlukla tanımadıkları kişiler olarak ifade edilmektedir (25). Ancak bazı olgularda güven ilişkisi içerisinde faili tanıyan ve yüksek alkol kullanımı dolayısıyla ehliyetini yitiren mağdurlara yönelik cinsel saldırı eylemleri, mağdurun bu zafiyetini bilen failler tarafindan daha kolay hale gelebilmektedir (26). MKCS olgularının çoğunda sadece mağdur değil failin de alkol tükettiği bilinmektedir. Dolayısıyla faillerin sözkonusu saldırı anında alkol tüketiminden kaynaklı agresyonları ile mağdurun faile karşı koyusu ve bunun sonucunda yaralanması arasında bir ilişki bulunmuştur (27).
Kültürler farklılaşsa dahi birçok konuda erkeklerin kadınlara yaklaşımı aynı olabilmektedir. Nijerya'da yürütülen bir çalışmada kadınların "erkek içkisi”" diye tabir edilen içkileri tüketmeleri toplumsal kabul görmemektedir. Ancak kadınlara seçenek olarak sunulan içki türleri ise tatlandırılmış fakat oldukça yüksek alkollü içkilerdir. Seçme hakkı kısıtlanan kadınlar yüksek alkollü içkileri tüketmek zorunda kaldıklarında erkeklere nazaran daha hızlı alkol tesiri altına girerek erkeklerin bu durumdan faydalanmaları olası hale gelmektedir. Buna karşın erkekler bira vb. gibi düşük alkol oranı olan içkileri tüketerek cinsel ilişki beklentisi ile kendilerini ayık konumda tutmaktadırlar (28).

Failin güç kullanıp kullanmaması da öngörülebileceği üzere mağdurun hâlihazırdaki intoksikasyon seviyesine bağlı kalmaktadır. Ehliyetin Olmadığı Cinsel Saldırı olguları ile MKCS olgularında fail herhangi bir silaha başvurmamaktadir $(1,4,31)$.

\section{Suçun İşlenişi (Modus Operandi)}

Zorbalığın kullanıldığı cinsel saldırı olgularından farklı olarak suçun işlenişi, MKCS olgularında tamamen failin sosyal ve linguistik yeteneğine bağlı kalmaktadır. Failin sahip olduğu bu nitelikler, amacına ulaşmasında ve sonrasında adli süreç için en önemli şahit olan mağdurun yaşadıklarının farkına varmaması adına faile kolaylık sağlamaktadır. Ayrıca suç ortamının hazırlanması için gerekli güveni ve yakınlığı sağlayabilmek amacıyla fail, mağduru ikna etmeye çalışabilir. Mağdurla yakın ilişkisi bulunan failin, mağdurun itirazlarına rağmen yaşananların gerçek olmadığını ikna etmesi de yine sözel yeteneğin gelişmiş olmasıyla açıklanabilir. Bazı durumlarda ise fail mağdura başka psikoaktif maddeler (kokain, ekstazi vs.) teklif edebilmekte ve ardından içkisine sedatif maddeler karıştırabilmektedir. Böylelikle savunmasında mağdurun aynı zamanda uyuşturucu kullanıcısı olduğu yönünde açıklamalarda bulunabilir. Kullandığı bu yolla fail, mağdurun adli süreçteki inandırıcılığını etkilemeyi hedeflemektedir (19). Fail mağdurun adli merciler karşısındaki inandırıcılığını zedelemek istese de mağdur da görülebilecek Travma Sonrası Stres Bozukluğu belirtileri travmatik cinsel saldırı yaşantısının belirteci olabilmektedir (29).

Failin işlediği suç genellikle 4 temel bileşene sahiptir (19):

Yöntem: Sedatif maddelere ulaşım ve maddenin mağdurun bilincine, dayanıklılığına ve hafizasına olan etkileriyle ilgili geniş bilgi sahibi olmak.

Ortam: Suç içeren eylem gerçekleşirken bölünmeyeceği ve kaçışının kolay olacağı, planı uygulamak için gereken alana sahip failin her şeyi kontrol altında tutabileceği bir mekân. 
Fırsat: Mağdurun güvenini kazandıktan sonra uygun ortamda yöntemini ortaya koyup suçu işleyebileceği an.

Tutuklanmadan ve yargı sürecinden kaçabileceği bir plan: Mağdur hala sedatif haldeyken ortamdan kaçma, mağduru yeniden giydirme veya alternatif senaryolar hazırlamak için gereken süreye ilişkin bir plan. Şayet mağdur failin hesapladığı zaman aralığından önce ayılırsa, mağduru ikna etmek ve kandırmak için uydurulmuş başka hikayeleri de içerir.

\section{MKCS'nin Tipolojisi}

MKCS'nin oportünist bir suç olduğu düşünülürse, firsatın sağlandığı her ortamda gerçekleşebileceğine dikkat edilmelidir. Kullanılan maddelerin türü ise sıklıkla failin ulaşımının olduğu maddelere göre değişiklik göstermektedir. Buradan hareketle MKCS'nin tipolojisi en iyi cinsel saldırının gerçekleştiği ortamla açıklanabilir. İş yerleri, sağlık kurumları ve sosyal ortamların hepsi failler tarafindan kullanılabilmektedir.

\section{1. İs Yeri Ortamında MKCS}

Aşina olunduğu üzere patronun yeni başlayan çalışanına, bir davette içkisine ilaç katmak suretiyle cinsel saldırıda bulunması birçok olguyla da literatürde yer almıştır. Bu ilişki içerisinde gerçekleşen MKCS'nin temelinde dominant işverenin, çalışanı üzerindeki erk talebi olabilir. Finansal ya da diğer değerlerle çalışanın riayetini kazanan işveren, çalışanın üzerinde fiziksel kontrol kazanma çabasına girebilmektedir. Evinden işini yöneten bir fail için, yerleşim yeri MKCS planını uygulayabilmesi için en uygun ortamdır. İçkinin ilaçlanması için gereken maddelerin ulaşılabilir yerlerde olması, sosyal becerilere sahip olmayan bir faile işini yapmak amacıyla gelen mağdura cinsel saldırısında büyük kolaylık sağlayabilir (30).

\subsection{Sağlık Kurumlarında MKCS}

Sağlık kurumlarında gerçekleşen MKCS olgularında sağlık profesyonellerinin ortam üstünlüğü ve sedasyon yaratan maddelere kolay erişimleri, planlı bir cinsel saldırıya yol açmaktadır. Farmakolojik bilgi birikimleri sayesinde suçu işleyip akabinde soru işaretlerine yer vermeyecek şekilde davranabilirler. Bir olguda çevresi tarafindan sevilen, saygıdeğer bir sağlık profesyoneli, yeni hastasıyla olması gerekenden daha uzun bir muayene seansı geçirdikten sonra hasta mağdur iç çamaşırının ters olmasından kuşkulanıp Cinsel Saldırı Kriz Merkezine başvuruyor. Yapılan toksikolojik analizlerden sonra mağdurun MKCS kurbanı olduğu anlaşılıyor (19).

Standart prosedür esnasında sedatif madde verilen hasta sonrasında olanların farkında değildir. Bu açıdan olası bir cinsel saldırı açıklanması ve kanıtlanması zor- dur. Adli süreçte yapılacak olan incelemeler bu kritik durumu detaylı bir biçimde ele almalıdır.

\subsection{Sosyal Ortamlarda MKCS}

Faillerin birçoğu sosyal ortamlardaki yakınlık ve kalabalığı kullanarak potansiyel hedeflerinin içkisini ilaçlamaya çalışır. Barlar, kulüpler, partiler ve buluşmalar bu açıdan kolaylaştırıcı etkiye sahiptir. Yapılan çalışmalarda bireylerin nasıl MKCS mağduru olduğu açıklanmaya çalışılmıştır. Krebs ve arkadaşları (2009) MKCS olgularında alkol başta olmak üzere bir miktar da psikoaktif madde kullanımının etkili olduğunu bildirmektedir (31). Yapılan başka bir çalışma ise, istemli bir şekilde yüksek düzeylerde alkol aldıktan sonra ehliyetini yitirmeleriyle cinsel saldırıya uğrayan kadınlar ile kendi iradeleri dışında intoksikasyona uğrayan kadınlar arasındaki farklar incelenmiştir. Araştırmanın sonuçlarına göre ise her 10 kadından 1 'inde mevcut olan MKCS öyküsü ile mağdur ergenken görülen alkol ve madde kullanım öyküsü arasında yüksek düzeyde bir ilişki tespit edilmiştir (32).

MKCS aynı zamanda birden fazla failin beraber işleyebildiği bir suç olgusudur. Yapılan çalışmalara göre, karşılaşılan olgularda mağdurun etkisiz halinden birkaç kişinin yararlandığ 1 bildirilmiştir (19). Bu olgularda öncelikli olarak iletişime geçip mağdurun güvenini kazanan bir baş fail vardır. Ardından mağdurun ehliyetinin olmamasıyla cinsel saldırıda bulunan başka failler gelmektedir.

Yukarıda tartışıldığı üzere MKCS olgusu çoğunlukla iyi planlanmış bir ortam ve düzenek gerektirmektedir. Failler çoğunlukla yüksek sosyal ve sözel beceri profiline sahip, seçtikleri kurbanlarını ikna edebilen ya da kurdukları yakınlık sayesinde kendilerine boyun eğdiren bireylerdir. Mağdurun güvenini kazanan failler sonuç olarak planlarını sergilemeye başlarlar. Daha basit MKCS olgularında da fail firsatları kollayıp en doğru zamanda hamlesini yapmaktadır.

\section{Sonuç}

Sonuç olarak ülkemizde MKCS'nin standart bir tanımı henüz bulunmamaktadır. MKCS'nin ruhsal, sosyal ve hukuki süreci de kapsayan bir tanımın yapılması bu olgulara yaklaşımlar açısından önem arz etmektedir. Dolayısıyla ülkemizde kapsamlı ve araştırmacılar tarafından kabul gören bir tanım ileriki araştırmalar ve toplumsal farkındalık yaratmak açısından yararlı olacağı düşünülmektedir (33).

Literatüre göre alkol MKCS'da en çok tespit edilen etken madde olmuştur. Alkol kullanımının sosyal ortamlar da dâhil olmak üzere yaygınlaştığı düşünüldüğünde MKCS riskinin sosyal ve bireysel faktörlerden dolayı ar- 
tabileceğine dikkat edilmelidir (34). Bazı durumlarda alkol ve psikoaktif maddenin beraber kullanıldığı da görülmektedir (11). Bazen de mağdurlar çok yüksek dozlarda alkol aldıktan sonra yaşadıkları MKCS hakkında alkole yönelik toleranslarını dikkate almadan içeceklerine psikoaktif madde eklendiğini iddia edebilmektedirler (33).

Özellikle mağdurun istemli bir biçimde psikoaktif madde kullandığı olgularda kolluk kuvvetlerine bildirim mağdurun çekinmesi ve suçluluk gibi hislerinden dolayı gecikebilmektedir (35). Maddenin sebep olduğu algıda ve bellekteki sorunlar ile birlikte otoriteye güvensizlik, inkâr, suçluluk ve utanç duygusu gibi nedenlerle mağdurun adli makamlara başvurusu gecikebilir. Bu gecikme günler veya haftaları bulabilir. Oysa 12 saatlik bir gecikme bile alkol ve GHB gibi vücuttu hızlı metabolize olan maddeler açısından delil kaybına neden olabilmektedir (34).

MKCS olguları çok disiplinli bir anlayışla yaklaşı1ması gereken olgulardır. Toksikolojik analizler ile MKCS şüpheleri aydınlatılabilmektedir. Örneğin Victorian Adli Tıp Enstitüsü'nde MKCS şüphesi ile başvuran olguların idrar ve kan örnekleri 24 saat içerisinde toplanırken şüpheli saldırı ve saldırının delilleri üzerinden 24 saat geçen olgularda birçok psikoaktif maddenin vücutta yarılanma ömrü açısından sonuç vermeyeceği bilgisi göz önünde bulundurularak sadece idrar örneği toplanmaktadır (34).

Birinci basamak sağlık hizmetlerinde görev yapan meslek elemanlarına MKCS olguları ile karşılaştıkları zaman mağdurlara nasıl yaklaşmaları gerektiğine yönelik eğitimlerin verilmesi gerekmektedir. MKCS olguları adli bilimlerin tıbbın ve hukukun birlikte çalışmak zorunda olduğu çok disiplinli bir yaklaşıma ihtiyaç duymaktadır. Meslek elemanları adli ve yasal süreçler hakkındaki farkındalıklarını koruyarak MKCS mağdurlarıyla iletişim halinde olmalıdır. Meslek elemanları aynı zamanda MKCS olgularında karşılaşılabilecek olası psikoaktif maddeler, maddelerin birey üzerindeki etkileri ve bu durumda neler yapılması gerektiği hakkında bilgilendirilmelidir (36).

Hall ve arkadaşlarına (2008) göre Kuzey İrlanda'da MKCS'ye yönelik artan yayınlar ve bilinçlendirme çalışmaları sonucunda MKCS bildirilerinin anlamlı bir şekilde arttığı bulgulanmıştır (37).

Ülkemizde modern anlamda Cinsel Saldırı Kriz Merkezlerinin yeterli sayıda ve nitelikte olamayışı cinsel saldırı olgularında mağdur için gerekli hatta hayati olan tıbbi, psiko-sosyal ve hukuki desteğin sağlanmasına engel teşkil etmektedir. MKCS gibi cinsel saldırı türlerine ve bunların sonuçlarına dikkat çekilmeli, gerekli merkezler ve bilinçlendirme kampanyaları ile bu konular gündemde tutulmalıdır.

\section{Kaynaklar}

1. Du Mont J, Macdonald S, Rotbard N, Asllani E, Bainbridge D, Cohen MM. Factors Associated with Suspected DrugFacilitated Sexual Assault. Canadian Medical Association Journal 2009;180(5):513-519. https://doi.org/10.1503/ cmaj.080570

2. Elliott SP, Burgess V. Clinical Urinalysis Of Drugs and Alcoholin Instances of Suspected Surreptitious Administration ("Spiked Drinks"). Science \& Justice 2005;45:129134. http://dx.doi.org/10.1136/emj.2006.040360

3. Madea B, Musshoff F. Knock-Out Drugs: Their Prevalence, Modes of Action, and Means of Detection. Deutsches Artzteblatt International 2009;106:341-347. DOI: 10.3238/arztebl.2009.0341

4. Kilpatrick DG, Resnick HS, Ruggiero KJ, Conoscenti LM, McCauley J. Drug-Facilitated, Incapacitated, and Forcible Rape: A National Study. National Criminal Justice Reference Service 2007;1-71.

5. Horvarth M. Brown J. Drug Assisted Rape and Sexual Assault: Definitional, Conceptual and Methodological Developments. Journal of Investigative Psychology and Offender Profiling 2005;2:203-210. DOI: 10.1002/jip.33

6. Du Mont J, Macdonald S, Kosa D. An Examination of Victim, Assailant, and Assault Characteristics Among Cases Classified As Predatory Drug-Facilitated Sexual Assault. Women's health issues 2016;26(4):393-400. https://doi. org/10.1016/j.whi.2016.05.010

7. Kilpatrick D, Edmunds C, Seymour AK. The National Women's Study. Arlington, Va: National Victim Center 1992.

8. Tjaden PG, Thoennes N. Extent, Nature, and Consequences of Rape Victimization: Findings From The National Violence Against Women Survey. 2006;1-42

9. Black MC, Basile KC, Breiding MJ, Smith SG, Walters ML, Merrick MT, Stevens MR. The National Intimate Partner and Sexual Violence Survey: 2010 Summary Report. Atlanta, GA: National Center for Injury Prevention and Control, Centers for Disease Control and Prevention, 2011;19:39-40. Available from: https://www.cdc.gov/violenceprevention/ pdf/nisvs_report2010-a.pdf.

10. AMCD, Report on Drug Facilitated Sexual Assault (DFSA). UK Advisory Council on the Misuse of Drugs 2007;1-18

11. Hurley M, Parker H, Wells, DL. The Epidemiology of Drug Facilitated Sexual Assault. Journal of clinical forensic medicine 2006;13(4):181-185. https://doi.org/10.1016/j. jcfm.2006.02.005

12. Littleton H, Grills-Taquechel A, Axsom D. Impaired And Incapacitated Rape Victims: Assault Characteristics and Post-Assault Experiences. Violence and victims, 2009;24(4):439-457

13. Richer LA, Fields L, Bell S, Heppner J, Dodge J, Boccellari A, Shumway M. Characterizing Drug-Facilitated Sexual Assault Subtypes and Treatment Engagement of Victims at A Hospital-Based Rape Treatment Center. Journal of interpersonal violence, 2017;32(10):1524-1542. DOI: $10.1177 / 0886260515589567$ 
14. Du Mont J, Macdonald S, Rotbard N, Bainbridge D, Asllani E, Smith N, Cohen MM. Drug-Facilitated Sexual Assault in Ontario, Canada: Toxicological and DNA Findings. J Forensic Leg Med. 2010;17(6):333-338. https://doi. org/10.1016/j.jflm.2010.05.004

15. Scott-Ham M, Burton F. Toxicological Findings in Cases of Alleged Drug-Facilitated Sexual Assault in The United Kingdom Over A 3-Year Period. J Clin Forensic Med 2005;12:175-186. https://doi.org/10.1016/j. jcfm.2005.03.009

16. Hindmarch I, ElSohly M, Gambles J, Salamone S. Forensic Urinalysis of Drug Use in Cases of Alleged Sexual Assault. J Clin Forensic Med. 2001;8:197-205. DOI: 10.1054/ jcfm.2001.0513

17. Boussairi A, Dupeyron J, Hernandez B, Delaitre D, Beugnet L, Espinoza P, Diamant-Berger O. Urine Benzodiazepines Screening of Involuntarily Drugged and Robbed or Raped Patients. J Toxicol Clin Toxicol. 1996;34(6):721-724.

18. Jones AW, Kugelberg FC, Holmgren A, Ahlner J. Occurrence of Ethanol and Other Drugs In Blood and Urine Specimens From Female Victims of Alleged Sexual Assault. Forensic Sci Int 2008;181:40-46. https://doi.org/10.1016/j. forsciint.2008.08.010

19. Welner M, Welner B. Drug-Facilitated Sex Assault In: Hazelwood RR, Burgess AW, editors. Practical aspects of rape investigation: A multidisciplinary approach 5th Edition. New York: CRC Press; 2017. p. 355-370.

20. Kernberg OF. The Narcissistic Personality Disorder and The Differential Diagnosis of Antisocial Behavior. Psychiatric Clinics of North America 1989;553-570.

21. Price DR. Personality disorders and traits. Mental and emotional injuries in employment litigation 1994;93-140.

22. Swan SC, Lasky NV, Fisher BS, Woodbrown VD, Bonsu JE, Schramm AT, Williams CM. Just A Dare or Unaware? Outcomes And Motives of Drugging ("Drink Spiking") Among Students At Three College Campuses. Psychology of violence 2017;7(2):253-264. http://dx.doi.org/10.1037/ vio0000060

23. Malamuth NM, Linz D, Heavey CL, Barnes G, Acker M. Using The Confluence Model of Sexual Aggression to Predict Men's Conflict With Women: A 10-Year FollowUp Study. Journal of personality and social psychology 1995;69(2):353-369.

24. Welner, M. The Perpetrators and Their Modus Operandi. In: LeBeau M, Mozayani A, editors. Drug facilitated sexual assault, London: Academic Press; 2001. p. 39-71.

25. Harrington NT, Leitenberg H. Relationship Between Alcohol Consumption and Victim Behaviors Immediately Preceding Sexual Aggression by An Acquaintance. Violence and Victims 1994;9:315-324.

26. Abbey A, BeShears R, Clinton-Sherrod AM, McAuslan P. Similarities and Differences In Women's Sexual Assault Ex- periences Based On Tactics Used By The Perpetrator. Psychology of Women Quarterly 2004;28:323-332. https://doi. org/10.1111/j.1471-6402.2004.00149.x

27. Abbey A, Buck PO, Zawacki T, Saenz C. Alcohol's Effects On Perceptions of A Potential Date Rape. J Stud Alcohol 2003;64(5):669-677.

28. Dumbili EW, Williams C. "If She Refuses to Have Sex With You, Just Make Her Tipsy": A Qualitative Study Exploring Alcohol-Facilitated Sexual Violence Against Nigerian Female Students. Journal of interpersonal violence. 2017;124. https://doi.org/10.1177/0886260517708761

29. Padmanabhanunni A, Edwards D. Treating The Psychological Sequelae of Proactive Drug-Facilitated Sexual Assault: Knowledge Building Through Systematic Case Based Research. Behavioral and Cognitive Psychotherapy 2012;41:371-375. https://doi.org/10.1017/ S1352465812000896

30. Welner M. The Drug Facilitated Sex Offender: Distinguishing Features and Histories. Paper at the present. AAFS Annual Meeting, Seattle, WA. 2001.

31. Krebs CP, Lindquist CH, Warner TD, Fisher BS, Martin SL. College Women's Experiences With Physically Forced, Alcohol- Or Other Drug-Enabled, and Drug-Facilitated Sexual Assault Before and Since Entering College. Journal of the American College of Health 2009;57(6):639-647. https:// doi.org/10.3200/JACH.57.6.639-649

32. Testa M, Livingston JA, Vanzile-Tamsen C, Frone MR. The Role of Women's Substance Use In Vulnerability to Forcible and Incapacitated Rape. Journal of Studies on Alcohol 2003;64(6):756-764.

33. Hall JA, Moore CBT. Drug Facilitated Sexual Assault-AReview. Journal of forensic and legal medicine 2008;15(5):291297. https://doi.org/10.1016/j.jflm.2007.12.005

34. Anderson LJ, Flynn A, Pilgrim JL. A Global Epidemiological Perspective on The Toxicology of Drug-Facilitated Sexual Assault: A Systematic Review. Journal of forensic and legal medicine 2017;47:46-54. https://doi.org/10.1016/j. jflm.2017.02.005

35. Valentine JL, Middleton R, Sparks C. Identification of Urinary Benzodiazepines and Their Metabolites: A Comparison of Automated HPLC and GC-MS After Immunoassay Screening of Clinical Specimens. J Anal Toxicol. 1996;20:416-424.

36. McBrierty D, Wilkinson A, Tormey W. A Review of DrugFacilitated Sexual Assault Evidence: An Irish Perspective. Journal of forensic and legal medicine, 2013;20(4):189197. https://doi.org/10.1016/j.jflm.2012.09.009

37. Hall J, Goodall EA, Moore T. Alleged Drug Facilitated Sexual Assault (DFSA) In Northern Ireland From 1999 to 2005. A Study of Blood Alcohol Levels. J Forensic Leg Med. 2008;15:497-504. https://doi.org/10.1016/j. jflm.2008.05.006 